\title{
Educação infantil no cenário brasileiro pós golpe parlamentar: políticas públicas e avaliação
}

Resumo: Este artigo tem por objetivo analisar as mudanças nas proposições da política pública de Educação Infantil, em especial as políticas relativas à avaliação concernente a esta etapa, em decorrência da troca de governo resultante do golpe parlamentar que teve seu desfecho no primeiro semestre de 2016.Para tanto, situa o percurso recente de elaboração de uma política de avaliação para essa etapa educacional, destacando as metas e estratégias do Plano Nacional de Educação (PNE), e o relaciona com outras políticas em curso, como a curricular, que tem atualmente como principal escopo a definição de uma Base Nacional Comum Curricular (BNCC). Identifica-se que a revogação da portaria que definia o Sistema Nacional de Avaliação da Educação Básica (SINAEB), que incluía a Avaliação da Educação Infantil (ANEI) e a apresentação de uma terceira versão da BNCC, focada em uma perspectiva curricular baseada em competências e habilidades e com ênfase na escrita na educação infantil, coloca em risco o processo de definição de uma política avaliativa descentrada do desempenho individual das crianças e preocupada com a qualidade da oferta da educação. Outro aspecto de atenção é quanto às alianças estabelecidas na definição das políticas educacionais, tendo em vista a identificação da participação de entidades privadas não só na execução das políticas, mas na sua formulação, o que revela uma clara opção por uma lógica privatista de governo.

Palavras-chave: Educação Infantil. Cenário Político pós golpe. Avaliação. BNCC.

\section{Children Education in the Brazilian scenario after parliamentary coup: Public policy and evaluation}

\begin{abstract}
This article aims to analyze the changes in the public police propositions of Children Education, in particular the evaluation policies concerning this stage, due to the change of government resulting from the parliamentary coup that had its end in the first half of 2016. Therefore, it sets the recent course of elaborating an evaluation policy for this educational stage, highlighting the goals and strategies of Plano Nacional de Educação (PNE) and links it to other ongoing policies, such as the curriculum, which currently has as its main scope the definition of a Base Nacional Comum Curricular (BNCC). It is identified that the revocation of the decree that defined the Sistema Nacional de Avaliação da Educaçãolnfantil (ANEI) and the presentation of a third version of BNCC, focused on a curricular perspective based on skills and abilities and with an emphasis on writing in children's education, jeopardizes the process of defining a descentralized evaluation policy on the individual performance of children and is concerned about the quality of education provision. Another aspect of attention is the aliancesestabilished in the definition of educational policies, in order to identify the participation of private entities not only in the implementation of policiebut in their formulation, which reveals a clear choice for privatist logic of government.
\end{abstract}

Keywords: Children Education. Scenario after parliamentary coup. Avaluation. BNCC.

\footnotetext{
I Doutora em Estudos da Criança pela Universidade do Minho-PT. Professora no DTPEN - Departamento de Teorias e Prática de Ensino da Universidade Federal do Paraná. E-mail: angelamscoutinho@gmail.com

2 Doutora em Educação pela Universidade Federal do Paraná. Professora no DTPEN - Departamento de Teorias e Prática de Ensino da Universidade Federal do Paraná. E-mail: moro.catarina@gmail.com
} 


\section{Introdução}

educação infantil constitui-se no Brasil enquanto prática social e política pública, e traz na sua
história a marca de um intenso movimento de luta, para assegurar o atendimento às crianças
em contextos coletivos de educação formal e como direito da criança. O avanço na discussão da área como parte da educação se efetiva com a inclusão na Constituição de 1988 da educação infantil como direito das crianças de 0 a 6 anos e com a promulgação da Lei de Diretrizes e Bases da Educação 9394/96, que reconhece a educação infantil como parte da educação básica.

Decorrente dessa inclusão na legislação educacional estão as políticas que versam sobre várias dimensões, formação de professores, currículo, avaliação. Desde a promulgação da Constituição em 1988 observamos campos de intensa disputa de concepções em torno dessas políticas, que revelam o papel do Estado na sua definição, execução e financiamento, geralmente na interlocução com outras entidades, principalmente as de caráter privado, que desde a década de 90 do século passado encontram espaço de atuação no setor público, ora com mais facilidade de atuação, ora se deparando com alguns movimentos de resistência.

Nesse contexto, o objetivo do presente artigo é analisar as mudanças nas proposições da política pública de Educação Infantil, em especial as políticas relativas à avaliação concernente a esta etapa, na troca de governo resultante do golpe parlamentar que teve seu desfecho no primeiro semestre de 2016. Para tanto, situa o percurso recente de elaboração de uma política de avaliação para essa etapa educacional, destacando as metas e estratégias do Plano Nacional de Educação (PNE), e o relaciona com outras políticas em curso, como a curricular, que tem atualmente como principal escopo a definição de uma Base Nacional Comum Curricular (BNCC) e apresenta riscos evidentes de retrocesso.

\section{Trajetória de uma política de avaliação para a educação infantil}

Ainda que na organização da educação nacional, a responsabilidade de oferta da educação infantil recaia principalmente ao ente municipal, o Ministério da Educação (MEC), tanto na esfera executiva, por intermédio da Coordenação Geral da Educação Infantil (COEDI), como na esfera normativa, pela atuação da Câmara da Educação Básica do Conselho Nacional de Educação (CEB/CNE,) vem assumindo sua parcela de compromisso com esta etapa, sobretudo a partir dos anos de 1990. Seja por intermédio de orientação técnico-pedagógica, de regulamentação e da implementação de programas que subsidiem as finalidades principais da Educação Infantil (a ampliação do Programa Nacional da Biblioteca Escolar (PNBE), que passou a fornecer livros de literatura, às instituições específicas para as crianças até os 6 anos e o Programa Nacional de Reestruturação e Aquisição de Equipamentos para a Rede Escolar Pública de Educação Infantil (PROINFÂNCIA), podem servir de exemplos). 
Em 2009, o MEC no documento "Indicadores da Qualidade na Educação Infantil" (BRASIL, 2009), articula a questão da qualidade com uma proposição avaliativa, mais especificamente para que cada instituição possa empenhar-se em um processo de auto avaliação. Além deste princípio, o documento implica a adesão deliberada pela equipe e comunidade educativa ampliada (direção, técnicos, professores, auxiliares, famílias e outras pessoas da comunidade interessadas) de cada unidade. O processo a ser empreendido requer a participação democrática, disposição para mudanças da cultura institucional, para a reflexão e exercício de autocrítica em relação às práticas educativas efetivadas no cotidiano institucional.

Nos anos que se seguiram foram surgindo diferentes tensões no cenário nacional em relação a avaliação pensada para a etapa da educação infantil, que indicavam a fragilidade de uma concepção própria de avaliação, diferenciada daquelas que vinham sendo efetivadas no âmbito da política nacional para as demais etapas e níveis de ensino, como a Provinha Brasil , o Sistema de Avaliação da Educação Básica $\left(\mathrm{SAEB}^{4}\right)$ e outras.

Em 2012, decorrido um ano de trabalho de um grupo de especialistas constituído pelo MEC, veio a público o documento "Educação Infantil: Subsídios para construção de uma sistemática de avaliação". Entre as discussões ali presentes podemos vislumbrar a proposição de uma política nacional de avaliação, que resguarda as especificidades para esta etapa inicial da Educação Básica e enfatiza a avaliação da oferta educativa. Ao mesmo tempo, a avaliação da criança aparece reafirmada como dispõe a Lei de Diretrizes e Bases da educação nacional (LEI no 9.394/1996) e as Diretrizes Curriculares Nacionais para a Educação Infantil (DCNEI) vigentes - Resolução CNE/CEB no 5/2009 (BRASIL, 2009a), sobretudo como competência da escola e de seus professores.

A partir de 2013, a coordenação da Diretoria de Avaliação da Educação Básica (DAEB) do Instituto Nacional de Estudos e Pesquisas (INEP), também em conjunto com alguns especialistas, em continuidade às atividades do Grupo de Trabalho do MEC, inicia a discussão para implementação da avaliação da Educação Infantil em âmbito nacional. Aproximadamente dois anos depois (maio de 2015), chega a propor uma minuta de portaria para a criação da Avaliação Nacional da Educação Infantil (ANEI 5), que tem como foco o monitoramento da oferta da Educação Infantil.

Quase simultaneamente o Plano Nacional da Educação (PNE - 2014-2024, Lei no 13.005/2014) traz em diferentes metas e estratégias os desafios relativos à qualidade e à avaliação da Educação Infantil. Em seu Art. $2^{\circ}$ a melhoria da qualidade da educação nacional é apresentada como uma das diretrizes desse plano decenal. No Art. 11, consta a discricionariedade acerca do Sistema Nacional de Avaliação da Educação Básica como "fonte de informação para a avaliação da qualidade da educação básica e para a orientação das políticas públicas". Ao se atentar às metas e estratégias atinentes à etapa educacional das crianças até os 6 anos de idade, encontramos a Meta 1, sobre a qualidade educativa e a avaliação,

${ }^{3}$ Avaliação instituída pelo MEC em 2007, de adesão também voluntária pelas redes de ensino municipal e estadual, para verificar o desempenho de crianças egressas do $1^{\circ}$ ano do Ensino Fundamental, em dois momentos ao longo do $2^{\circ}$ ano.

${ }^{4}$ O SAEB foi criado em 1990 pelo Ministério da Educação para aferir o rendimento dos alunos do ensino fundamental e médio por meio de uma matriz de referência curricular formulada com base no ensino por competências, a qual passa a ser referenciada mais tarde nos parâmetros curriculares nacionais.

${ }^{5}$ Mesmo a minuta não tendo sido assinada, a proposição foi incluída no âmbito do Sistema Nacional de Avaliação da Educação Básica (Sinaeb). 
observando um padrão nacional de qualidade em articulação com peculiaridades locais (estratégia 1.1); o acesso e a equidade (estratégias 1.3,1.4); a construção e reestruturação de estabelecimentos (estratégia 1.5); a preservação das especificidades da Educação Infantil e articulação com a etapa seguinte (estratégia 1.13); uma estratégia específica sobre a avaliação da Educação Infantil (1.6), a ser implantada até o segundo ano de vigência do Plano, 2016, e realizada "a cada dois anos, com base em parâmetros nacionais de qualidade, a fim de aferir a infraestrutura física, o quadro de pessoal, as condições de gestão, os recursos pedagógicos, a situação de acessibilidade, entre outros indicadores relevantes".

As Metas 4, 7, 19 e 20 também se relacionam à Educação Infantil. Na Meta 4 propõe-se a universalização do atendimento para a população com deficiência, transtornos globais do desenvolvimento e altas habilidades ou superdotação, preferencialmente na rede regular, sem desconsiderar a necessidade de serviços especializados para as crianças de 4 e 5 anos. A Meta 7, na Estratégia 7.4 refere sobre o processo contínuo de auto avaliação das escolas de educação básica, por meio da constituição de instrumentos de avaliação que orientem as dimensões a serem fortalecidas - a elaboração de planejamento estratégico, a melhoria contínua da qualidade educacional, a formação continuada dos(as) profissionais da educação e o aprimoramento da gestão democrática. Ainda que a Meta 7 trate do Índice de Desenvolvimento da Educação Básica (IDEB), que não se relaciona à Educação Infantil, o conteúdo da na Estratégia 7.4 se aplica a Educação Infantil por referir-se a um processo contínuo de auto avaliação das escolas de educação básica, por meio da constituição de instrumentos de avaliação que orientem as dimensões a serem fortalecidas - a elaboração de planejamento estratégico, a melhoria contínua da qualidade educacional, a formação continuada dos(as) profissionais da educação e o aprimoramento da gestão democrática.

Outra meta, que consideramos estar articulada à qualidade da oferta da Educação Infantil, é a Meta 19, por tratar da busca em efetivar a gestão democrática da educação, estimulando a "participação e a consulta de profissionais da educação, alunos(as) e seus familiares na formulação dos projetos políticopedagógicos, currículos escolares, planos de gestão escolar e regimentos escolares, assegurando a participação dos pais na avaliação de docentes e gestores escolares". Também interessa a Meta 20, sobre a ampliação do investimento público em educação para 10\% (dez por cento) do Produto Interno Bruto (PIB) até o final da vigência do Plano e, sobre a implementação do Custo Aluno Qualidade (CAQ) como parâmetro para o financiamento de todas as etapas e modalidades da educação básica (Estratégia 20.7). E a Estratégia, 20.11, que propõe a aprovação até 2016 da Lei de Responsabilidade Educacional.

A ANEI em consonância com o estabelecido no atual PNE foi incluída no âmbito do Sistema Nacional de Avaliação da Educação Básica (SINAEB ${ }^{\circ}$ ), a fim de avaliar e aprimorar as políticas públicas de educação. O Art. 8o estabelecia entre outras questões: “a) a Avaliação Nacional da Educação Infantil, com ciclo avaliativo bianual, a iniciar-se em 2017, com o objetivo de realizar diagnósticos sobre as condições de oferta da educação infantil pelos sistemas de ensino público e privado no Brasil, aferindo a

${ }^{6}$ O SINAEB foi sancionado pela Portaria n 369, do Ministério da Educação, promulgada em 5 de maio de 2016 (publicada no Diário Oficial da União no 86, de 6 de maio de 2016, Seção 1, pág. 26), pelo Ministro Aloysio Mercadante. 
infraestrutura física, o quadro de pessoal, as condições de gestão, os recursos pedagógicos, a situação de acessibilidade, entre outros indicadores contextuais relevantes, além de fornecer subsídios aos sistemas de ensino para a construção de políticas públicas que possibilitem melhoria na qualidade da educação infantil." Contudo, a crise política e institucional que se abateu sobre o país, também incorreu na dissolução do SINAEB7, ainda durante o impedimento não definitivo da presidente eleita Dilma Roussef. Entre as possíveis consequências desta última decisão está a fragilização do PNE vigente e das metas ali colocadas para enfrentamento das condições atuais na área.

Contemporaneamente o projeto "Formação da Rede em Educação Infantil: Avaliação de Contexto", foi outra ação articulada com a COEDI/MEC que por intermédio da pesquisa, buscou discutir e contribuir para a formulação de uma política nacional de avaliação em Educação Infantil (BRASIL, 2015) em consonância com os princípios democráticos e participativos focalizando uma abordagem metodológica formativa e em contexto (BONDIOLI; SAVIO, 2013). O documento "Contribuições para a Política Nacional: a avaliação em educação infantil a partir da avaliação de contexto" está estruturado em três partes: uma discute a relação entre qualidade na Educação Infantil brasileira e avaliação de contexto, recuperando documentos e ações já desenvolvidas na trajetória nacional recente; outra se volta a perspectiva teóricometodológica de avaliação de contexto e apresenta uma síntese do percurso da pesquisa realizada; e a última traz uma proposição que dialoga com a elaboração e a revisão de instrumentos de avaliação em Educação Infantil, focalizando a oferta da experiência educativa (BRASIL, 2015).

A perspectiva que enfoca a avaliação da oferta educativa contrapõe a visão da avaliação da criança de forma descontextualizada. Para Donatella Savio: "não se observam-documentam as crianças individuais, surpreendidas e suspensas em seus comportamentos, descritos sem um "antes", um "durante" e "sobre", um "depois"” (SAVIO, 2006, p. 6). Bondioli (2014, p. 59) assevera que:

Mesmo no caso em que se possuíssem instrumentos confiáveis para realizar tal verificação, faltaria estabelecer se e em qual medida os níveis de performance alcançados pelas crianças (p. ex., nas capacidades linguísticas, expressivas, motoras, etc.) poderiam ser considerados "produtos" ou "resultados" do processo formativo. De fato, é sabido que a determinar tais resultados concorrem múltiplas variáveis (por exemplo, fatores temperamentais e constitucionais, ambiente social e cultural, modalidades comunicativas no âmbito da família), das quais a frequência à creche não é o único nem o mais relevante.

Podemos compreender de tais posicionamentos, que o resultado do desempenho individual das crianças não serve para medir a qualidade da educação e dos cuidados por elas recebidos na instituição de Educação Infantil. O caminho deve ser o inverso, pois:

[...] a avaliação de contexto permite problematizar a avaliação da aprendizagem ao colocar os objetivos educacionais alcançados pelas crianças em articulação com a qualidade da formação que elas recebem (o contexto relacional e de aprendizagem oferecidos), no sentido de permitir visualizar e discutir o impacto real da experiência educacional sobre os educandos (BRASIL, 2015, p. 40-41).

7 O SINAEB foi dissolvido pela Portaria 981 (publicada no Diário Oficial da União de 26/08/2016, n 165, Seção 1, pág. 16), na data de 26 de agosto de 2016, pelo Ministro da Educação Francisco Mendonça Filho.

${ }^{8} \mathrm{O}$ projeto foi uma ação da Universidade Federal do Paraná com outras universidades brasileiras (Universidade Federal de Minas Gerais, Universidade Federal do Rio de Janeiro e Universidade do Estado de Santa Catarina), além da universidade italiana Università degli studi di Pavia/Itália - e contou com a parceria técnica e financeira da Secretaria de Educação Básica do Ministério da Educação. 
A tônica desse movimento - desde os "Indicadores de Qualidade da Educação Infantil", passando pelos grupos de trabalho do MEC e do INEP, o amplo debate sobre o PNE, culminando na ANEI e também a pesquisa acerca de avaliação de contexto - foi sempre o envolvimento de muitos interlocutores em uma perspectiva dialógica e democrática, com intensa participação das instituições de ensino superior públicas, dos movimentos sociais e entidades ligadas aos sistemas públicos.

\section{O golpe e a ruptura com a perspectiva democrática}

A perspectiva democrática, que acompanhou o processo de discussão da avaliação da/na educação infantil descrito na seção anterior, mesmo atravessada por muitos confrontos e disputas de poder, sofreu uma guinada com a instituição do golpe parlamentar à presidência do Brasil. Todo o processo de destituição da representatividade democraticamente definida pelos votos de cidadãos e cidadãs que culminou com a retirada da presidenta do cargo de chefe de Estado teve graves consequências para o campo da educação e, em especial, para a educação infantil.

Uma das ações mais problemáticas para a Educação com a instituição do novo governo foi a aprovação da emenda constitucional no 95 em dezembro de 2016, que prevê o congelamento por 20 anos dos gastos públicos em várias áreas, dentre elas a social. Com tal aprovação teremos recuo no investimento em educação, sendo que o valor de $6 \%$ do PIB investido até então já não era suficiente, então o que esperar com a previsão de diminuição de recurso em um cenário marcado por tantas desigualdades?

O cenário de cortes e visível defesa da privatização da educação, assentados em uma perspectiva política de Estado de exceção, criou condições favoráveis para que o governo justifique o não cumprimento de metas e estratégias do PNE, como a estratégia 1.6, que como já mencionado previa o início da avaliação da educação infantil a partir de 2016. Tal medida relaciona-se a um conjunto de definições que estão articuladas e que visam selar um acordo com entidades privadas na definição e execução das políticas educacionais.

Nesse sentido, destacamos a relação entre a política de avaliação e demais políticas educacionais, como a curricular. O escopo atual da definição de uma política curricular é a elaboração de uma Base Nacional Comum Curricular (BNCC). A definição de uma BNCC está prevista desde a Constituição Federal de 1988, ainda que apenas para o ensino fundamental, e na LDB 9394/96. Em 2010 foi iniciado o processo de construção da BNCC por meio do "currículo em movimento", que gerou um conjunto de textos de consulta pública que acabou por não se configurar como uma base. Em 2015 o movimento foi retomado e em junho deste mesmo ano é aprovada a portaria 592 que institui a Comissão de Especialistas para a Elaboração de Proposta da BNCC. Em um primeiro momento a educação infantil não estava incluída no processo de discussão, o que só ocorre com a solicitação da COEDI/ MEC.

Para a participação no processo foi constituído um grupo de especialistas da área, que se dedicou a escrita de textos preliminares que foram amplamente debatidos. A primeira versão indicava o caminho escolhido para a definição da BNCC para a educação infantil, mas era uma versão bastante abreviada, já na segunda versão há um texto mais extenso, que explicita de modo mais claro algumas 
escolhas. Destaca-se nessas versões da BNCC a clara opção por seguir o que determina o documento "Diretrizes Curriculares Nacionais para a Educação Infantil” (BRASIL, 2009a).

No corpo do texto identifica-se a definição de direitos de aprendizagem: aprender a conhecer-se, a conviver, a explorar, a brincar, a participar e a expressar-se, assim como a organização por campos de experiência: o eu, o outro e o nós; corpo, gestos e movimentos; traços, sons, cores e imagens; escuta, fala pensamento e imaginação; espaços, tempos, quantidades, relações e transformações.

Um ponto polêmico do texto é a definição de objetivos de aprendizagem, que remetem para uma perspectiva homogeneizante no contexto de um documento que se propõe base curricular nacional, além do que tais objetivos podem ser facilmente utilizados em uma transposição para conteúdos, que preencherão apostilas cuidadosamente elaboradas pelos interessados sistemas de ensino privados que produzem materiais didáticos.

Embora não seja consenso na área a necessidade de definição de uma BNCC para a educação infantil, o modo como o processo vinha sendo encaminhado permitia que em diferentes contextos, nas cinco regiões do país, o debate acerca do que constitui a experiência educativa com as crianças de 0 a 6 anos ocorresse. No entanto, a publicização da terceira versão do texto em abril de 2017 revelou um significativo retrocesso. Isso porque os especialistas que participaram da elaboração da primeira e segunda versões do texto foram afastados do processo e não houve espaços de participação para a sociedade civil.

Cabe destacar dois aspectos da mudança na terceira versão da BNCC que afetam de modo direto a relação com a avaliação. O primeiro deles é a inclusão de uma perspectiva curricular baseada em competências e habilidades, situando o desenvolvimento em determinados aspectos e no indivíduo e não no seu processo de constituição humana, a partir de uma educação integral. Outro ponto, especificamente na educação infantil, é a mudança de um dos campos de experiência "escuta, fala pensamento e imaginação" para "oralidade e escrita", o que claramente demarca a ênfase no ensino da escrita para as crianças ainda na educação infantil, desconsiderando as demais dimensões que constituem o trabalho com as linguagens, principalmente a imaginação, elemento central ao se pensar as experiências das crianças pequenas.

A mudança de perspectiva revela uma concepção de criança como capital humano, que precisa desde muito cedo ser preparado para o mercado de trabalho, o que é incoerente com a concepção de criança presente nas DCNEI (BRASIL, 2009a), como centro do planejamento curricular e como sujeito histórico e de direitos, ou seja, há um reconhecimento da criança como cidadã e que possui marcas de seus pertencimentos de acordo com o contexto histórico em que vive. As DCNEI definem ainda, "[...] que, nas interações, relações e práticas cotidianas que vivencia, constrói sua identidade pessoal e coletiva, brinca, imagina, fantasia, deseja, aprende, observa, experimenta, narra, questiona e constrói sentidos sobre a natureza e a sociedade, produzindo cultura" (BRASIL, 2009a).

Com a destituição dos especialistas na tarefa de sistematizar o texto da BNCC observamos o avanço de representações de organizações da sociedade civil, sobretudo, fundações empresariais. Nesse sentido, é importante retomar o que indicam Adrião et al (2012), que nas assessorias para gestão 
educacional prevalece a contratação de instituições privadas do terceiro setor. Preocupa o fato de ser possível observar uma mudança no lugar que o Terceiro Setor ocupa, que segundo as autoras era de executor, parece-nos que nesse momento o Estado se desresponsabiliza da tarefa de formulação e atribui também ao Terceiro Setor essa função, já que o texto da BNCC contou (e ainda conta) com atuação direta de fundações privadas.

Não há dúvidas que muitos interesses estão por trás de tal atuação, que não só aqueles utilizados nos discursos das entidades privadas da preocupação com uma educação de qualidade e com equidade para todos. Decorrente da BNCC estão políticas nacionais de formação de professores, de materiais e tecnologias educacionais, de infraestrutura e de avaliação, ou seja, grandes nichos de atuação do capital privado, que poderá produzir material didático, com pacotes envolvendo formação de formação, assim como materiais e cursos preparatórios para avaliações de larga escala, dentre outros materiais e serviços.

Ainda na análise do quadro de mudanças, a concepção expressa na BNCC está articulada à aprovação da portaria 826 de julho de 2017, que trata do Pacto Nacional pela Alfabetização na Idade Certa9 ${ }^{9}$ PNAIC) e inclui a pré-escola em sua abrangência:

As ações do PNAIC terão como foco os estudantes da pré-escola e do ensino fundamental, cabendo aos professores, coordenadores pedagógicos, gestores escolares e gestores públicos uma responsabilidade compartilhada no alcance do direito da criança de escrever, ler com fluência e dominar os fundamentos da Matemática no nível recomendável para sua idade. (BRASIL, 2017, p. 20 grifos nossos)

Os eixos que compõem as ações do PNAIC são: formação continuada; materiais didáticos, literatura e tecnologias educacionais; avaliação e gestão. No que diz respeito à avaliação, a portaria define:

[...] a) avaliação externa universal ao final do $5^{\circ}$ e $9^{\circ}$ ano do ensino fundamental, aplicada pelo INEP; b) avaliação externa universal do nível de alfabetização, aplicada pelo INEP; c) avaliações periódicas, aplicadas pelas próprias redes de ensino, a partir de instrumentos padronizados e o registro em sistema adequado ao monitoramento das ações aprovadas no Plano de Gestão; d) avaliação de aprendizagem realizada periodicamente pelas próprias escolas, para orientar ações de apoio e reforço pedagógico aos alunos nas dimensões de Leitura, Escrita e Matemática. [...] (BRASIL, 2017, p. 20)

O fato de não estar explícita a inclusão da pré-escola nos processos de avaliação previstos não a torna isenta de participar, tendo em vista que a portaria utiliza o termo "nível de alfabetização" e "avaliação da aprendizagem" de modo indiscriminado, o que abre espaço para a interpretação de que as crianças de 4 a 6 anos podem ser incluídas nesses processos.

Considera-se que, com a aprovação da versão final da BNCC, que possivelmente ocorrerá após as cinco audiências públicas nacionais promovidas pelo Conselho Nacional de Educação e com a instituição das ações do PNAIC, serão tornadas públicas as definições sobre a avaliação da e na educação infantil, mas com qual perspectiva? Na definição das avaliações que compunham o SINAEB havia dois grupos de indicadores que revelam as perspectivas adotadas. No quadro abaixo podemos identificar as avaliações que compunham o SINAEB e quais indicadores as constituíam:

${ }^{9}$ Essa portaria também versa sobre o Programa Novo Mais Educação (PNME). 


\begin{tabular}{|l|l|}
\hline \multicolumn{1}{|c|}{ AVALIAÇÃO } & \multicolumn{1}{|c|}{ INDICADORES } \\
\hline Avaliação Nacional da Educação Infantil (Anei) & Indicadores de avaliação institucional. \\
\hline Avaliação de alfabetização - Provinha Brasil & $\begin{array}{l}\text { Indicadores de rendimento escolar, referentes ao } \\
\text { desempenho dos estudantes; } \\
\text { Indicadores de avaliação institucional. }\end{array}$ \\
\hline Avaliação Nacional de Alfabetização (ANA) & $\begin{array}{l}\text { Indicadores de rendimento escolar, referentes ao } \\
\text { desempenho dos estudantes; } \\
\text { Indicadores de avaliação institucional. }\end{array}$ \\
\hline Avaliação Nacional da Educação Básica (Aneb) & $\begin{array}{l}\text { Indicadores de rendimento escolar, referentes ao } \\
\text { desempenho dos estudantes; } \\
\text { Indicadores de avaliação institucional. }\end{array}$ \\
\hline $\begin{array}{l}\text { Avaliação Nacional do Rendimento Escolar - } \\
\text { Prova Brasil (Anresc) }\end{array}$ & $\begin{array}{l}\text { Indicadores de rendimento escolar, referentes ao } \\
\text { desempenho dos estudantes; } \\
\text { Indicadores de avaliação institucional. }\end{array}$ \\
\hline
\end{tabular}

Quadro 1: Sintese das avaliações e indicadores que constituem o SINAEB, de acordo com a portaria $n^{\circ} 369$.

Como é possível observar no quadro a única avaliação que não inclui indicadores de rendimento escolar, que são aferidos por meio exames nacionais de avaliação e de dados pertinentes apurados pelo censo escolar da educação básica, é a educação infantil. A relação da avaliação com a definição de uma BNCC que destaca a escrita como função da educação infantil, com clara concepção cognitivista acerca da elaboração de conhecimento pelas crianças pequenas e a inclusão da pré-escola no PNAIC, nos leva a problematizar se também a avaliação da educação infantil incluirá indicadores de desempenho individual, como ocorre nas avaliações para as demais etapas, ou se manteremos a perspectiva de avaliar os sistemas e a oferta, considerando características como o perfil das crianças e do corpo dos profissionais da educação, as relações entre dimensão do corpo docente, do corpo técnico e do corpo discente, a infraestrutura física, as condições de gestão, os recursos pedagógicos, a situação de acessibilidade, a auto avaliação?

No caso da primeira possibilidade se confirmar, quais proficiências das crianças pequenas seriam avaliadas, nas linguagens, nas interações e nas brincadeiras? Como avaliar tais proficiências? Ou teremos ênfase na avaliação da aquisição da escrita? Não é possível aceitar a avaliação de desempenho individual na educação das crianças de 0 a 6 anos, tendo em vista o objetivo da educação integral das crianças e a luta histórica para se chegar a tal definição.

O momento é de atenção, governos neoliberais fazem políticas privatizantes e centradas nas regras do mercado, contexto que ganha legitimidade no cenário brasileiro, portanto, a suspensão de definições construídas ao longo dos últimos anos sugere uma pausa para assumir uma relação que, sempre esteve presente na definição das políticas públicas, mas agora tem um contexto ainda mais favorável, a sua determinação na negociação com o empresariado. 


\section{Considerações finais}

A proposta de analisar as mudanças nas proposições da política pública de educação infantil, em especial as políticas relativas à avaliação concernente a esta etapa, em decorrência da troca de governo resultante do golpe parlamentar que teve seu desfecho no primeiro semestre de 2016 é decorrente da leitura do cenário desafiador que se apresenta à definição de uma agenda de lutas contra ao retrocesso no que tange algumas conquistas da área.

Nesse sentido, buscamos destacar que na trajetória da definição de uma política de avaliação da educação infantil, desde 2009 com a proposição dos Indicadores de Qualidade, observa-se um campo de tensionamento entre diferentes interesses, sobretudo, na perspectiva de disputa de espaço por parte de representações da iniciativa privada, mas a abertura democrática vivenciada até o golpe parlamentar se instituir permitia o debate e o enfrentamento dessas questões mediante intensa produção acadêmica e atuação de movimentos sociais.

A constituição de grupos de especialistas e desenvolvimento de pesquisas que procuraram contribuir com a elaboração de uma política de avaliação que considere as especificidades da área da educação infantil, assim como contribua com a definição de uma concepção de qualidade assentada na participação democrática dos sujeitos, foi dissolvida a medida que os interesses das organizações de caráter privado tiveram a sua participação legitimada, não só na execução das políticas, assim como na sua formulação.

O cenário é altamente preocupante, porque o protagonismo que representações de entidades privadas possuem no contexto da definição das políticas, implica que o parco recurso que será destinado à educação nos próximos 20 anos será destinado com prioridade à essas entidades, que consideram que a educação das crianças pequenas deve atuar na formação de capital humano devidamente preparado para o mercado de trabalho.

Nesse quadro, quais são as alternativas que se colocam? A retomada da democracia participativa é uma necessidade urgente. Para Milton Santos (2008) a democracia foi esvaziada no seu sentido real, não há representativa de todos cidadãos e cidadãs, há um sistema eleitoreiro que enfraquece e fragiliza os que já estão à margem.

No caso da educação infantil, a luta histórica pelo seu reconhecimento enquanto etapa educacional, que os profissionais que atuam com as crianças são professores, que necessitam de formação específica, que o currículo precisa se pautar no objetivo da sua educação integral e na consideração das suas experiências e no seu direito de acessar o amplo acervo de conhecimentos, sobretudo, a elaboração das suas culturas e, principalmente, por recursos que permitam a expansão da oferta e a sua qualidade, já revela o quanto esta etapa sempre esteve à margem, mesmo que tenha tido significativos avanços nos campos legal e pedagógico.

A definição de uma política de avaliação da educação infantil em uma perspectiva que considera as especificidades da área estava em curso, sua suspensão pode significar que essa não será a concepção de avaliação que se manterá, até porque ela não se sustenta em um contexto de definição de políticas para a educação infantil baseada na antecipação de aprendizagens que caracterizam o ensino fundamental e na 
ideia de desenvolvimento de competências e habilidades. Nos cabe denunciar o retrocesso e continuar na luta, mesmo que isso signifique um intenso e desgastante enfrentamento.

\section{Referências}

ADRIÃO, Theresa et al. As parcerias entre prefeituras paulistas e o setor privado na política educacional: expressão de simbiose?In: Educação e Sociedade. Campinas, v. 33, n. 119, abr.-jun. 2012, p. 533-549. Disponível em http://www.cedes.unicamp.br Acesso em: janeiro de 2014.

BONDIOLI, Anna. Indicadores operativos e análise da qualidade: razões e modos de avaliar. In: CIPOLLONE, Laura (Org.). Instrumentos e indicadores para avaliar a creche: um percurso de análise da qualidade. Trad. Luiz Ernani Fritoli. Curitiba: Ed. UFPR, 2014. p. 47-72.

BONDIOLI, A.; SAVIO, D. (Orgs.). Participação e qualidade em educação da infância: percursos e compartilhamento reflexivo em contextos educativos. Trad. Luiz Ernani Fritoli. Curitiba: Editora UFPR, 2013.

BRASIL. Portaria no 826, de 7 de julho de 2017. In: Diário Oficial da União. № 130, segunda-feira, 10 de julho de 2017.

Base Nacional Comum Curricular. Disponível em: http://basenacionalcomum.mec.gov.br/ Acesso em: maio de 2017.

Portaria no 369. Institui o Sistema Nacional de Avaliação da Educação Básica (Sinaeb), de 5 de maio de 2016. Diário Oficial da União, Brasília, no 86, 6 maio 2016, Seção 1, pág. 26.

Contribuições para a Política Nacional: a avaliação em educação infantil a partir da avaliação de contexto. Curitiba: Imprensa/UFPR; Brasília: Ministério da Educação. Secretaria de Educação Básica. Coordenação Geral de Educação Infantil - MEC/SEB/COEDI, 2015, 104p.

Lei no 13.005, de 25 de junho de 2014. Aprova o Plano Nacional de Educação - PNE e dá outras providências. Diário Oficial da União, Brasília, DF, 26 jun. 2014.

Indicadores da Qualidade na Educação Infantil. Brasília, DF: MEC/SEB/COEDI, 2009.

Resolução CNE/CEB n ${ }^{\circ}$ 05, de 17 de dezembro de 2009. Fixa as Diretrizes Curriculares Nacionais para a Educação Infantil. Brasília, DF, 18 dez., 2009a. 
Lei $n^{\circ}$. 9.394, de 20 de dezembro de 1996. Estabelece as Diretrizes e Bases da Educação Nacional. Brasília: 1996. Disponível em: < http://www.planalto.gov.br/ccivil_03/leis/19394.htm >. Acesso em: 15 abr. 2013

SANTOS, Milton. Por uma outra globalização do pensamento: do pensamento único à consciência universal. $17^{\mathrm{a}}$ ed. Rio de Janeiro: Record, 2008.

SAVIO, Donatella (a cura di). Il portfolio alla scuola dell'infanzia: Un pretesto per ricercare e negoziare identità. Bergamo: Edizioni Junior, 2006.

Recebido em: 16/08/2017

Aprovado em: 26/11/2017 